\title{
LA EDUCACIÓN COMO PRÁCTICA DE "DOMESTICACIÓN": LA SINGULARIDAD Y LA DIVERSIDAD AMENAZADAS
}

\author{
EDUCATION AS A PRACTICE OF "DOMESTICATION": \\ SINGULARITY AND DIVERSITY THREATENED
}

\section{María Fernanda Felice}

Universidad Nacional de Rosario, Argentina

ferfelice22@hotmail.com

Recibido: 21 de julio de 2021

Aprobado: 15 de octubre de 2021

Publicado: 31 de diciembre de 2021

Cita sugerida: Felice, M. F. (2022). La educación como práctica de "domesticación": la singularidad y la diversidad amenazadas. Revista de la Escuela de Ciencias de la Educación.

1(17), 97-110

\section{RESUMEN}

El presente trabajo fue desarrollado en la instancia de evaluación final correspondiente a la Especialización en Alfabetización e Inclusión, carrera de posgrado que ofrece el Centro de Estudios Interdisciplinarios (UNR). El mismo se propuso reflexionar acerca de ciertas prácticas educativas que, en reiteradas ocasiones, se convierten en prácticas de "domesticación" que atentan contra la diversidad inherente a todos los sujetos y a todos los aprendizajes.

Se desarrolló un estudio de casos específico, que analizó el proceso de construcción de la lectura y la escritura de una niña. Es un trabajo de intervención fonoaudiológica, en el cual se explicitan intervenciones terapéuticas para promover el desarrollo del lenguaje y el aprendizaje de la lengua escrita.

Se observa que la institución escolar no ha sido capaz de valorar los saberes que la niña expone, como lectora y escritora. Las dificultades registradas remiten, fundamentalmente, a las diferencias entre oralidad y escritura, las normas impuestas por los géneros discursivos y los aspectos no alfabéticos del aprendizaje de la lengua escrita.

El trabajo interdisciplinario permitió correr la mirada del "déficit", para tomar en consideración las posibilidades de la niña, y promovió avances significativos en el aprendizaje de la lengua escrita.

Palabras clave: Prácticas educativas - Aprendizaje escolar - Lectura y escritura

- Diagnósticos - Patologización de las infancias. 
Revista de la Escuela de Ciencias de la Educación. 2022, Año 18 1(17). 97-110. Enero a junio. Felice, M.F. La educación como práctica de "domesticación": la singularidad y la diversidad amenazadas.

\section{ABSTRACT}

This work was developed in the final evaluation instance corresponding to the Specialization in Literacy and Inclusion, a postgraduate degree offered by the Center for Interdisciplinary Studies (UNR). It set out to reflect on certain educational practices that, repeatedly, become "domestication" practices that threaten the diversity inherent in all subjects and all learning.

A specific case study was developed, which analyzed the process of constructing a girl's reading and writing. It is a speech therapy intervention work, in which therapeutic interventions are made explicit to promote language development and the learning of written language.

It is observed that the school institution has not been able to assess the knowledge that the girl exposes, as a reader and writer. The difficulties recorded refer, fundamentally, to the differences between orality and writing, the norms imposed by the discursive genres and the non-alphabetic aspects of learning the written language.

The interdisciplinary work made it possible to look at the "deficit", to take into account the possibilities of the girl, and promoted significant advances in the learning of the written language.

Keywords: Educational practices - Reading and writing - Diagnosis - School learning - Childhood pathologization.

\section{INTRODUCCIÓN}

El presente trabajo fue elaborado en la instancia de evaluación final correspondiente a la Especialización en Alfabetización e Inclusión, carrera de posgrado que ofrece el Centro de Estudios Interdisciplinarios de la Universidad Nacional de Rosario. El mismo se propuso reflexionar acerca de ciertas prácticas educativas que, en reiteradas ocasiones, se convierten en prácticas de "domesticación" que atentan contra la singularidad y la diversidad inherentes a todos los sujetos y a todos los aprendizajes.

Simonns y Maschelein (2014) sostienen que la escuela domestica porque pretende que los conocimientos, que tienen un sentido escolar, se conviertan en saberes productivos o ligados a competencias que habría que adquirir.

En este sentido, Freire (2004) expresa que sería ingenuo esperar que las clases dominantes desarrollasen una forma de educación que le permitiese a las clases dominadas percibir las injusticias sociales en forma crítica. Por este motivo, considera que la educación bancaria persiste en contexto educativo, en tanto resulta conveniente que los/as estudiantes se conviertan en seres de adaptación, que se ajusten a la realidad que imponen los opresores.

Las ideas antes citadas se vinculan con las concepciones desarrolladas por Ferreiro (1994). Esta autora explica que, desde su fundación, a la escuela se le ha encomendado la tarea de crear una única nación y un único pueblo. Su tarea principal fue gestar idénticas subjetividades, capaces de responder a un determinado arquetipo de ciudadanía.

En la actualidad los/as estudiantes, que presentan una discapacidad, una dificultad o una diferencia respecto de lo que el sistema educativo estima "aceptable", deben adaptarse al calendario y la currícula escolar. Mientras que 
Revista de la Escuela de Ciencias de la Educación. 2022, Año 18 1(17). 97-110. Enero a junio. Felice, M.F. La educación como práctica de "domesticación": la singularidad y la diversidad amenazadas.

aquellos/as alumnos/as -que habitan contextos de vulnerabilidad social- se convierten en portadores de patologías o certificados de discapacidad. Puesto que la escuela continúa presentando dificultades para valorar las diferencias. Al respecto, Puiggrós (1990) afirma que, en la educación argentina, históricamente se ha recurrido a modelos biológicos y orgánicos para explicar las diferencias sociales de los estudiantes. Argumenta que "para ello era necesario definir los sujetos conflictivos en escalas biológicas y psicológicas y no reconocer el origen político de las desigualdades sociales" (p.9).

En estos tiempos es habitual encontrarse con sujetos, que son portadores de diagnósticos o certificados de discapacidad, a pesar de no presentar ninguna patología. Estos/as niños/as suelen ser estigmatizados/as porque el proceso de alfabetización no es entendido desde su complejidad, y porque no son mirados desde la singularidad que signa su devenir como estudiantes, lectores y escritores.

Esta realidad se vincula con la era a la que asistimos, fuertemente, signada por la patologización de las infancias y adolescencias. Se habla de patologización, cuando los problemas cotidianos de niñas, niños y adolescentes son interpretados, rápidamente, como trastornos mentales o psiquiátricos, ocasionados por causas neurobiológicas o genéticas. Estas clasificaciones son consideradas rótulos o etiquetas y no verdaderos diagnósticos, porque no contemplan los determinantes del sujeto, su contexto familiar y social, al mismo tiempo, que desestiman la complejidad de los procesos de desarrollo y aprendizaje.

\section{DESARROLLO}

\section{Fundamentos teóricos}

El presente trabajo pretende destacar que la educación -entendida como un derecho humano- debe ofrecer oportunidades de encuentro con las culturas, el lenguaje, la lengua escrita, las experiencias y los saberes, en una dialéctica permanente entre educadores y educandos, atendiendo a la historia y la realidad de los sujetos.

En este sentido, resulta de singular relevancia considerar los aportes de la perspectiva vigotskiana y constructivista para comprender el proceso de aprendizaje de la lengua escrita. Al respecto, Castorina (2012) expresa que Ferreiro se pregunta cómo teorizan las niñas y los niños sobre la escritura, cómo formulan hipótesis e interpretan las marcas gráficas producidas históricamente.

Es decir, en las grandes interrogantes que orientaron sus investigaciones sobre la escritura, se encuentra la problemática acerca del pasaje de un estado de menor a mayor conocimiento. En cambio, a los seguidores de Vygotsky les interesa estudiar la lengua escrita como un instrumento sociocultural que promueve efectos en el desarrollo infantil y transforma la conciencia humana. En efecto, se formulan interrogantes diferentes, aunque necesarios para comprender la complejidad del proceso de aprendizaje de la lectura y la escritura.

La perspectiva constructiva considera que el aprendizaje de la lengua escrita no remite a la mera producción de marcas gráficas, así como la lectura no 
Revista de la Escuela de Ciencias de la Educación. 2022, Año 18 1(17). 97-110. Enero a junio. Felice, M.F. La educación como práctica de "domesticación": la singularidad y la diversidad amenazadas.

implica el simple desciframiento de las mismas, por el contrario, convoca a la interpretación de mensajes de distinto tipo y diversa complejidad.

Los/as niños/as construyen activamente el conocimiento acerca de este nuevo sistema de representación lingüística, que difiere del lenguaje oral, y comienzan a emprender este camino mucho antes de ingresar a la escuela.

Porque tal como lo enunciara Ferreiro (1994) la escritura no es un objeto escolar, sino que es patrimonio de la cultura, resultado del esfuerzo colectivo de la humanidad.

La perspectiva vygotskiana destaca que el aprendizaje de la lengua escrita implica un extenso proceso de apropiación cultural, en el cual el lenguaje se convierte en la herramienta mediatizadora por excelencia, en tanto todos los aprendizajes se gestan en la comunicación verbal entre las personas, en el entramado de prácticas sociales que acontecen entre los sujetos y su comunidad.

\section{Objetivos e interrogantes de la investigación}

Los objetivos propuestos son:

- Reflexionar respecto de aquellas prácticas educativas que menosprecian los saberes previos de los/as estudiantes, y que vacían de significación el aprendizaje de la lengua escrita.

- Indagar acerca de las estrategias discursivas que el sujeto indagado pone en juego al momento de escribir un texto, atendiendo a sus saberes como lector y escritor.

- Evaluar los aportes de la intervención fonoaudiológica en el proceso de construcción de la escritura y la lectura, a partir del análisis de una secuencia de textos escritos por el sujeto investigado.

- Interpretar los riesgos del etiquetamiento temprano ${ }^{1}$ y sus efectos en el contexto educativo.

Los interrogantes que promovieron este trabajo son los siguientes:

- Más allá de la propuesta formulada por el "Modelo Social de la Discapacidad" ¿la institución escolar es capaz de atender a la singularidad y las diferencias devenidas en los aprendizajes?

- ¿Los/as docentes toman en consideración los saberes previos y las conceptualizaciones que los/as niños/as realizan en el proceso de construcción de la lectura y la escritura?

- ¿Cuáles son los efectos que promueve la patologización de las infancias en el contexto de la educación? ¿Cómo impacta en la subjetividad de las niñas y los niños?

- ¿Cuáles son los aportes que los/as profesionales de la salud, educadores/as y especialistas en alfabetización e inclusión pueden ofrecer en el marco de la educación inclusiva?

\footnotetext{
${ }^{1}$ Esta expresión remite al contexto actual, signado por la patologización de las infancias y adolescencias. Desde esta perspectiva, se procura rotular o etiquetar rápidamente cualquier síntoma o malestar, sin atender a los tiempos del desarrollo y de los aprendizajes. De esta manera, se recurre a los diagnósticos propuestos por los Manuales de los Trastornos Mentales que ponderan la dimensión biológica de la salud y no contemplan la singularidad, la historia y el contexto de los sujetos.
} 
Revista de la Escuela de Ciencias de la Educación. 2022, Año 18 1(17). 97-110. Enero a junio. Felice, M.F. La educación como práctica de "domesticación": la singularidad y la diversidad amenazadas.

Para responder a estos objetivos e interrogantes, se desarrolla un estudio de casos que analiza el proceso de construcción de la lectura y la escritura de una niña, llamada Inés. Se toma en consideración su historia personal y escolar que se explicitará más adelante. Se trata de un trabajo de intervención fonoaudiológica, en el cual se explicitan determinadas intervenciones terapéuticas para la promoción del desarrollo del lenguaje y del aprendizaje de la lengua escrita.

A partir del análisis de sus producciones escritas y de los obstáculos devenidos en su trayectoria escolar, se cuestiona a las prácticas educativas que desatienden los saberes de los/as estudiantes y desestiman las construcciones que van realizando a fin de convertirse en lectores/as y escritores/as. Asimismo, se advierte sobre los riesgos del etiquetamiento temprano que estigmatiza a las niñas y los niños condenándolos, en reiteradas oportunidades, al fracaso dentro y fuera del aula.

Se aborda esta problemática desde una mirada crítica, a partir los aportes ofrecidos por diversas teorías que se oponen a una concepción meramente biologicista del sujeto de aprendizaje, que resaltan la complejidad del proceso de alfabetización y la necesidad de gestar una educación que valore las diferencias.

En este sentido, se propone "poner en tela de juicio" a aquellos enfoques que consideran que el proceso de construcción de la lectura y la escritura puede ser reducido a la enseñanza de un código y al entrenamiento de ciertas habilidades perceptivo-motoras. Enfoques que se vinculan con la era a la que asistimos, fuertemente, marcada por la patologización de las infancias y las certezas diagnósticas promocionadas por los Manuales de los Trastornos Mentales (DSM)2.

Se entiende que los/as profesionales de la salud, educadores/as y especialistas en alfabetización e inclusión tienen la responsabilidad de trabajar por una escuela inclusiva que reconozca la complejidad del aprendizaje de la lengua escrita y valore la singularidad de cada estudiante.

\section{Procedimientos para la obtención de datos}

Para llevar adelante el presente estudio de casos, se desarrollaron entrevistas, observaciones y revisión de informes. Se procedió a la recolección de datos vinculados a la historia personal y escolar del sujeto indagado. Se trata de Inés, una niña de diez años, quien se encontraba cursando el cuarto grado en una escuela privada de la ciudad de Rosario, en el marco de un proyecto de integración sostenido por sus docentes, su psicopedagoga y su fonoaudióloga, sin intervención de la escuela especial núcleo.

Desde el discurso, por el que Inés arriba a la consulta, se señalan dificultades en la comunicación, el lenguaje y el aprendizaje escolar. Se tomó en consideración los informes realizados por las terapeutas intervinientes, las valoraciones de sus docentes y su familia; así como también las percepciones, ideas y sensaciones que la niña expresa en torno a sus aprendizajes.

\footnotetext{
${ }^{2}$ Se trata de una serie de manuales creados por la Asociación Americana de Psiquiatría que propone una clasificación de trastornos psiquiátricos o mentales.
} 
Revista de la Escuela de Ciencias de la Educación. 2022, Año 18 1(17). 97-110. Enero a junio. Felice, M.F. La educación como práctica de "domesticación": la singularidad y la diversidad amenazadas.

Por otra parte, se realizó la interpretación de una secuencia de producciones escritas y revisadas por Inés, a fin de analizar el proceso de construcción de la escritura y la lectura.

\section{La historia de Inés}

La familia de la Inés arriba a la consulta y expresa que su hija ha presentado dificultades para comunicarse y armar lazos con otras personas, aunque reconoce que ha ido superando algunos de esos obstáculos. Explica que presenta dificultades en el aprendizaje escolar y que ha transitado por diversos espacios terapéuticos desde los cuatro años de edad: fonoaudiología, psicología y psicopedagogía. Acude a la consulta con los informes elaborados por las terapeutas que le habían brindado atención a Inés.

Los Informes explicitan los resultados obtenidos de una serie de tests y protocolos de evaluación. Estas pruebas tienen por misión cuantificar conductas atípicas y síntomas que, al ser agrupados, constituirán un determinado cuadro.

En consecuencia, la respuesta terapéutica es el ofrecimiento de una batería de técnicas reeducativas que procuran entrenar ciertas habilidades, arrasando contra todo rasgo de singularidad posible y vaciando de significación a la lengua escrita.

Los diagnósticos formulados por las profesionales intervinientes remiten a cuadros explicitados en los Manuales de los Trastornos Mentales (DSM):

Dificultades Específicas del Aprendizaje (DEA) y Trastorno de la Comunicación Social Pragmática (actualmente conocido como Trastorno del Espectro Autista o TEA). Desde esta perspectiva, cualquier dificultad, síntoma o malestar puede ser tipificado y clasificado bajo el nombre de una patología que siempre es producida por causas neurobiológicas o genéticas.

Por otra parte, sus maestras explican que les preocupa la "extrañeza" de algunos de sus comportamientos, tal como "su modo de expresarse" y su "rigidez" al momento de trabajar en el aula. Estas expresiones se vinculan con los indicadores, que se exponen para concientizar sobre el Trastorno del Espectro Autista, cada 2 de abril, fecha en la que se desarrollan campañas en medios de comunicación y redes sociales.

Los riesgos que promueve la necesidad de nombrar cualquier diferencia o dificultad en términos relativos a una patología remiten, por un lado, a la estigmatización de los/as estudiantes en el contexto educativo y, por otra parte, a la falsa ilusión que provoca en el universo adulto. Porque, desde esta perspectiva, el problema es exclusivo de la niña o del niño y, en consecuencia, la escuela, la familia y los/as docentes no tendrían demasiado por hacer. De esta manera, la responsabilidad del aprendizaje escolar recae, irremediablemente, en los/as alumnos/as.

En contraposición con el discurso de las terapeutas intervinientes, Inés muestra interés por participar de las instancias dialógicas. Se observa que la niña se expresa utilizando una "lengua neutra", hace uso de una entonación, expresiones y conjugaciones verbales que no son propias de nuestro español. A pesar de estos obstáculos, la niña muestra intención de comunicarse y reconoce que le resulta una tarea dificultosa en el contexto escolar. Manifiesta sus deseos de conquistar nuevas amistades. 
Revista de la Escuela de Ciencias de la Educación. 2022, Año 18 1(17). 97-110. Enero a junio. Felice, M.F. La educación como práctica de "domesticación": la singularidad y la diversidad amenazadas.

Se registran ciertas dificultades en el proceso de apropiación de la lengua materna y en el desarrollo de su lenguaje. Esto condiciona su interacción social, la organización de discursos orales y escritos, como así también, la comprensión de contenidos escolares más complejos.

\section{Los saberes de Inés}

Inés es una lectora apasionada. En cada sesión, se acerca con algunos de sus libros para compartirlos. Ha leído cuentos de Mempo Giardinelli, Laura Devetach, María Elena Walsh, Ema Wolf, Silvia Schujer, Graciela Montes, entre otros valiosos/as autores/as. Además, esto demuestra que su familia ha hecho una apuesta por Inés, a pesar de las dificultades devenidas en el aprendizaje escolar, ofreciéndole interesantes encuentros con la literatura.

La niña suele realizar recomendaciones literarias. Explica que "los libros con más dibujos y menos palabras son mejores para los niños pequeños", y que "los cuentos más largos son mejores para los chicos grandes".

Inés se interesa por la escritura de cuentos. Crea, escribe y revisa sus historias con suma atención. Esta tarea surge de instancias literarias, lúdicas y dialógicas compartidas en el contexto del consultorio.

Por otra parte, es importante destacar que Inés es capaz de advertir ciertas ideas y arquetipos que subyacen a la enseñanza propuesta por la escuela.

Aunque ella no sepa ni una pizca de pedagogía, entiende que la institución escolar estima que todas las niñas y todos los niños deben aprender lo mismo, al mismo tiempo, y del mismo modo. Es decir, consigue advertir que ciertas prácticas educativas se sostienen en el paradigma de la "normalidad".

Esta afirmación surge de una instancia literaria en la que se le propone compartir la lectura de un cuento llamado "Cuero negro, vaca blanca", escrito e ilustrado por Pablo Bernasconi (2010). Se trata de una historia sobre una vaca que quiere quitarse las manchas para ser distinta a las demás. Ante tantos intentos fallidos, la protagonista decide recuperar sus manchas y se alegra de volver a ser una vaca.

La niña relata, dibuja y escribe la historia. Cierra su producción escrita asegurando que la vaca "volvió a ser normal" y explica que "ser normal es ser igual a todos".

En este sentido, es posible inferir que Inés considera que quienes fueran "diferentes" portarían el estigma de la "anormalidad". De algún modo, es capaz de reconocer que la escuela continúa presentando dificultades para trabajar con las diferencias y valorar la singularidad de cada sujeto en el proceso de aprendizaje escolar.

\section{Las producciones escritas por Inés}

Se le propone a la niña escribir un cuento a partir de dos consideraciones. En primer lugar, porque se entiende que las prácticas de lectura y escritura son imprescindibles para promover avances en el aprendizaje de la lengua escrita. En segundo término, porque se considera que la construcción de relatos narrativos se presenta como un recurso valioso para la organización del lenguaje interior, que debe ponerse a disposición para la creación de sentidos. Es decir, se comprender que la narración, la escritura, la lectura y la revisión de los propios 
Revista de la Escuela de Ciencias de la Educación. 2022, Año 18 1(17). 97-110. Enero a junio. Felice, M.F. La educación como práctica de "domesticación": la singularidad y la diversidad amenazadas.

textos constituyen estrategias de intervención que pretenden propiciar efectos terapéuticos en el lenguaje, el proceso de alfabetización y el aprendizaje escolar. Inés decide escribir una historia de amor prohibido llamada "Los amores principales" y trabaja con el texto en distintos encuentros. Para realizar esa actividad, utiliza la computadora. Lee sus producciones, realiza correcciones e introduce cambios hasta que decide culminar ese proceso, asegurando que ha llegado a la versión final del cuento.

Luego se le solicita que revise el texto, a fin de que pudiera ser dirigido a niñas y niños que cursan primer grado, Inés decide crear un nuevo cuento. Expresa que "a los nenes chiquitos no le interesan los romances". Por ese motivo, aborda otra temática y escribe un relato vinculado a la escuela. El mismo se titula "El día escolar".

\section{Resultados e interpretación de los datos}

Se le propone a la niña escribir un cuento. Inés decide narrar una historia llamada "Los amores principales". Se trata de un relato que versa sobre una historia de amor prohibido.

Luego de sucesivas instancias de escritura y lectura, se le sugiere revisar el texto para que el mismo pudiera ser dirigido a niñas y niños que concurren al primer grado. Inés se detiene a pensar y asegura que ese cuento no es apropiado. Explica que "a los nenes chiquitos no le interesan los romances". Entonces crea otra historia llamada "El día escolar".

Al respecto, De Beaugrande y Dressler (1997) afirman que

si se parte de la base de que un texto es un documento de decisiones, selecciones y combinaciones, la mayor parte de los textos son significativos en virtud de todas las alternativas posibles que podrían haberse elegido en lugar de las que se prefirieron (p.69).

Desde luego, Inés ha tomado una serie de decisiones a fin de construir relatos significativos, a pesar de los obstáculos a los cuales debió enfrentarse.

En sus producciones, se registran interesantes progresos respecto de la organización del texto y los aspectos vinculados a las reglas ortográficas impuestas por el sistema de escritura.

La primera de sus producciones escritas no cuenta con ningún signo de puntuación. Luego de leer el texto, Inés advierte el error. Entonces incluye dos tipos de marcas gráficas que le permiten ordenar sus producciones escritas.

Coloca puntos para separar las frases e introduce el uso de comas, a fin de enumerar los nombres de algunos personajes que aparecen en escena hacia el final de la historia.

Lee con detenimiento palabras que revisten cierta complejidad por su estructura o extensión. Corrige algunos errores de tipeo y la omisión de ciertas letras. Además, comienza a preguntar por la ortografía de algunos vocablos con la intención de confirmar el modo correcto de escritura.

La niña toma decisiones respecto de la edición de sus textos, selecciona la tipografía y el tamaño de la letra. Decide que ambos estén escritos en imprenta mayúscula, elige la fuente Algerian 14 y explica que es una letra apropiada para 
Revista de la Escuela de Ciencias de la Educación. 2022, Año 18 1(17). 97-110. Enero a junio. Felice, M.F. La educación como práctica de "domesticación": la singularidad y la diversidad amenazadas.

cuentos infantiles. Respecto de la última producción realizada, considera necesario anexar algunas imágenes a su relato para motivar a sus lectores/as, puesto que se trata de niñas y niños pequeños. Selecciona dibujos de internet que representan a los/as protagonistas de la historia.

Los obstáculos que se registran en sus textualizaciones escritas se vinculan, fundamentalmente, con las diferencias existentes entre la oralidad y la escritura, con las normas que impone cada género discursivo y con los aspectos no alfabéticos del aprendizaje de la lengua escrita.

Al respecto, Ferreiro (1994) explica que, para que un sujeto sea capaz de pensar acerca de las relaciones existentes entre la oralidad y la escritura, es necesario que realice una compleja operación psicológica de objetivación del habla. Y, en esa objetivación, la escritura misma juega un rol fundamental; en tanto que adquirió la lengua oral en situaciones de comunicación efectiva, en interacciones sociales, en el encuentro con otras personas. Por lo cual, sabe para qué sirve la comunicación lingüística. Pero al tratar de comprender la escritura debe objetivar la lengua, es decir que, debe convertirla en un objeto de reflexión. Debe descubrir que existen múltiples maneras de decir lo mismo, tanto al hablar como al escribir, y construir entonces un "meta-lenguaje" para hablar sobre el lenguaje, convertido ahora en objeto de reflexión.

En el proceso de escritura, lectura y revisión, Inés ha sido capaz de reflexionar acerca de sus producciones escritas, a pesar de los errores registrados.

Por el momento, la niña no utiliza determinados recursos literarios y marcas gráficas propias del relato de ficción. Sin embargo, posee saberes en torno a las particularidades del texto narrativo. Conoce su estructura, la cual determina que al inicio deben presentarse los personajes, el escenario y el tiempo en el que acontecerán los hechos de la historia, y que luego surgirá un conflicto que será resuelto en el final del cuento.

Asimismo, reconoce que las narraciones ficcionales deben atender a las inquietudes de los/as posibles lectores/as. Entiende que la tipografía de letra, la extensión del texto, la temática y la introducción de imágenes son decisiones que el autor o la autora debe considerar, atendiendo a la edad y los intereses de sus destinarios/as.

Utiliza formas canónicas de inicio y cierre "había una vez" y "fin" e introduce diálogos entre los personajes. Sin embargo, aún no toma en consideración las marcas gráficas que debieran acompañarlos, tales como guiones, dos puntos, signos de exclamación e interrogación.

Se registran repeticiones, puesto que Inés aún no apela al uso de recursos literarios tales como la sinonimia y la elipsis.

Por otra parte, se observan errores de tipo ortográfico y, en ningún caso, la niña incluye tildes o acentos gráficos.

Se observan dificultades en la segmentación de algunas partículas relacionantes que sólo adquieren sentido en el contexto lingüístico, y que no remiten a palabras o categorías lexicales claras. Estos conectores suelen ser enlazados en reiteradas oportunidades.

En este sentido, es posible afirmar que Inés comete errores que son propios del proceso de aprendizaje de la lengua escrita. Algunos de ellos se 
Revista de la Escuela de Ciencias de la Educación. 2022, Año 18 1(17). 97-110. Enero a junio. Felice, M.F. La educación como práctica de "domesticación": la singularidad y la diversidad amenazadas.

relacionan con los aspectos no alfabéticos del sistema y otros, con las normas establecidas por el discurso narrativo.

Al respecto, Vygotsky (1977) explica que la escritura requiere de un control consciente y voluntario por parte del sujeto, que convoca a la abstracción de los aspectos sonoros del habla y de su destinatario. Es decir que, quien escribe debe representarse mentalmente al lector para poder crear su mensaje y proveer al texto de claves que guíen el proceso de reconstrucción de los sentidos.

Por su parte, Alvarado (2013) sostiene que es en la práctica de la escritura donde cobran sentido los aprendizajes lingüísticos, donde se hacen conscientes los procesos de selección y combinación de las unidades de la lengua y las reglas que los rigen. Además, explica que las restricciones impuestas por el lenguaje escrito, por su independencia de los contextos de acción y percepción, posibilita las formas de pensamiento abstracto y categorial.

De este modo, la escritura promueve el desarrollo de la metacognición porque el acto de escribir obliga a un análisis más preciso, a realizar razonamientos fundamentados, justificar las excepciones, aclarar las posibles contradicciones, elaborar y planificar ordenadamente. Permite la revisión de las ideas y los modos de expresarlas al momento de crear una producción escrita.

$\mathrm{Si}$ se comparan las primeras cuatro producciones correspondientes al cuento "Los amores principales" y la textualización final, Ilamada "El día escolar", es posible advertir los progresos conquistados por Inés.

En este sentido, las instancias de escritura narrativa, lectura, revisión y reescritura de sus propios textos le permitieron progresar respecto del proceso de alfabetización y de la organización de su lenguaje interior para la creación de relatos. Porque, para culminar con la versión final del primer cuento, Inés llevó adelante un arduo trabajo que le implicó realizar cuatro producciones. Mientras que el último texto fue resuelto de una manera más efectiva y clara, a partir de una sola textualización escrita.

Bereciartua (2008) sostiene que:

(...) no existe un punto concreto en el que pueda decirse que se ha realizado la producción de un texto de una manera definitiva, sino que, a lo sumo, puede detectarse lo que los autores llaman un umbral de finalización en el que el productor textual considera que el resultado obtenido es satisfactorio con respecto al propósito que pretendía alcanzar (p.154).

En efecto, es posible inferir que Inés consiguió valerse del trabajo realizado en las instancias de escritura del primer relato para lograr planificar, luego, su versión final y alcanzar su meta. La lectura y revisión de sus producciones iniciales le permitieron progresar y mejorar no sólo su producción textual final sino, además, producir una única versión de su segundo relato de manera ordenada y coherente en su sentido.

Por otra parte, Pètit (2015) afirma que componer narraciones es una necesidad antropológica. El relato es esencial para organizar nuestra experiencia, porque es nuestro medio específicamente humano de poner en orden los acontecimientos del tiempo. Se comprende que el relato de historias se presenta 
Revista de la Escuela de Ciencias de la Educación. 2022, Año 18 1(17). 97-110. Enero a junio. Felice, M.F. La educación como práctica de "domesticación": la singularidad y la diversidad amenazadas.

como una estrategia imprescindible para promover la comunicación, el desarrollo del lenguaje y el aprendizaje de la lengua escrita.

\section{CONCLUSIÓNES}

\section{Acerca del proceso de construcción de la lectura y la escritura del sujeto indagado}

La niña cuenta con valiosos saberes como lectora y escritora. Respeta la estructura narrativa y algunas características propias de los textos literarios.

Toma decisiones como autora, elige la temática del relato e interviene en la edición del texto pensando en sus posibles destinatarios/as.

Inés es capaz de escribir, leer y revisar sus producciones advirtiendo algunos de los errores cometidos. Procura enmendarlos y avanzar en el proceso de producción textual.

Se registran errores que se vinculan, fundamentalmente, con la complejidad inherente al aprendizaje de la lengua escrita. Algunos remiten a los aspectos no alfabéticos del sistema de escritura y otros, a las normas previstas para la producción de textos narrativos.

Cabe mencionar que las dificultades presentes en su lenguaje promovieron ciertos obstáculos al momento de realizar producciones escritas. Sin embargo, la creación de relatos propició avances en los discursos construidos por Inés.

Las instancias de lectura y escritura propuestas invitaron a Inés a reflexionar acerca de la construcción de sentidos y relatos.

La secuencia de textos elaborados por la niña revela los progresos conquistados en el aprendizaje de la lengua escrita. El primero de ellos le implicó un arduo trabajo, ya que realizó cuatro producciones hasta alcanzar la versión final de "Los amores principales". Mientras que, el segundo texto titulado "El día escolar" fue resuelto de una manera más clara y efectiva a partir de la escritura de una única versión. En este sentido, podría hipotetizarse que las sucesivas prácticas de lectura y escritura, en el primer caso, le permitieron a Inés, en el segundo, organizar un relato coherente en una sola versión.

Al respecto, Bettelheim (1983) afirma que aprender a leer es un desafío y conseguirlo, una enorme conquista. Explica que la mayoría de las niñas y los niños aprende a leer, antes o después, más o menos bien. Pero sólo una minoría se deleita leyendo. Porque por desgracia, frecuentemente, la lectura se presenta como la habilidad de descifrar y descifrar es, esencialmente, una actividad sin sentido, un proceso de mero reconocimiento. Asegura que "sólo cuando empezamos a responder personalmente al contenido del texto y nos abrimos a su mensaje vamos más allá de un simple descifrado y comenzamos a percibir significados" (Bettelheim, 1983, p.44).

Sin dudas, las prácticas de lectura y escritura, como así también las instancias narrativas y literarias han propiciado avances en el proceso de construcción de la lengua escrita.

Acerca de los interrogantes vinculados a las prácticas educativas es posible advertir que la escuela continúa sosteniendo una visión mecanicista del aprendizaje de la escritura, en tanto pondera la caligrafía y la ortografía en desmedro de los sentidos construidos por la niña en sus textualizaciones escritas. 
Revista de la Escuela de Ciencias de la Educación. 2022, Año 18 1(17). 97-110. Enero a junio. Felice, M.F. La educación como práctica de "domesticación": la singularidad y la diversidad amenazadas.

El etiquetamiento temprano, que marcó la historia de la niña, ha dejado ciertos estigmas en su trayectoria escolar. Sus maestras han estado demasiado atentas a los diagnósticos formulados, desestimando sus saberes y construcciones en torno al aprendizaje de la lengua escrita.

A pesar de la propuesta formulada por el "Modelo Social de la Discapacidad" y la inclusión educativa, los arquetipos basados en el paradigma de la "normalidad" aún persisten en la institución escolar. Motivo por el cual, las docentes han presentado ciertas dificultades para atender a la singularidad y las diferencias devenidas en los aprendizajes de Inés.

Al respecto, la niña reconoce esos obstáculos y expresa que algunos contenidos escolares le resultan complejos porque ella aprende de un modo distinto. En cierta medida, Inés advierte que el sistema educativo impone tiempos y condiciones idénticas para todas las niñas y todos los niños.

Por último, cabe destacar que el trabajo interdisciplinario entre terapeutas y docentes permitió correr la mirada del "déficit" para tomar en consideración las posibilidades de la niña. El abordaje compartido entre los/as profesionales de la salud y de la educación promovió avances significativos en el proceso de alfabetización y el aprendizaje escolar de Inés.

En este sentido, resulta imprescindible que los/as especialistas en alfabetización e inclusión desarrollen intervenciones terapéuticas y pedagógicas que aborden la complejidad inherente al aprendizaje de la lengua escrita, atendiendo a la singularidad de cada niña o niño.

\section{REFLEXIONES FINALES}

Ferreiro (1994) sostiene que, desde su fundación, la escuela pública de las nuevas naciones tuvo dificultades para trabajar con la diversidad. Pero, a pesar de sus esfuerzos por eliminar las diferencias, éstas han subsistido. Las primeras, que fueron reconocidas, ponían el énfasis en el rendimiento escolar y le fueron endilgadas a determinados grupos sociales o a niños/as pertenecientes a esos grupos. De esta manera, la escuela pública de los países latinoamericanos pasó de la heterogeneidad negada a la heterogeneidad reconocida como un mal inevitable. Pero la causa de esas diferencias se ubicó siempre en el interior del niño/a -procurando hallar un déficit o una patología- o en algo exterior a la escuela vinculado a la carencia de estímulos en el medio familiar, social o cultural.

La institución escolar no era responsable por las diferencias y, por lo tanto, debía luchar por exterminarlas.

El fracaso escolar, históricamente, le ha sido adjudicado al niño/a o, en su defecto, a su familia o grupo social de pertenencia. De manera que los/as docentes, la escuela, el sistema educativo, el Estado parecieran no tener responsabilidad alguna en el proceso de aprendizaje y sus avatares posibles.

En la actualidad, el enfoque propuesto por los Manuales de los Trastornos Mentales (DSM) ha colaborado en ese sentido y conseguido dejar su huella en la escuela. Desde esta perspectiva, el aprendizaje se circunscribe a la enseñanza de una serie de habilidades perceptivas y motoras que deben ser entrenadas. Las niñas y los niños han dejado de ser sujetos atravesados por su historia y su cultura, para convertirse en cerebros y genes que alojan la causa de todos sus 
Revista de la Escuela de Ciencias de la Educación. 2022, Año 18 1(17). 97-110. Enero a junio. Felice, M.F. La educación como práctica de "domesticación": la singularidad y la diversidad amenazadas.

posibles males. Además, han creado nuevas clasificaciones que no se restringen al contexto de la salud. Por el contrario, se replican en el ámbito educativo para interpretar las dificultades que las niñas y los niños presentan al momento de aprender.

En este sentido, ciertas prácticas educativas y clínicas pretenden "normatizar" los tiempos de aprendizaje y desarrollo, a través de una serie de categorizaciones o clasificaciones, en tanto consideran que las niñas y los niños pertenecen a una colectividad infantil relativamente homogénea. Desde este enfoque, se insiste con la concepción de una niñez modelo, prototipo o standard.

Una niñez alejada de la diversidad, la época y el contexto histórico del cual es parte. Una niñez que puede ser clasificada de acuerdo al orden predictivo y normativo, que imponen las ciencias de la salud positivistas y el sistema educativo disciplinador.

Es imprescindible recordar que el aprendizaje de la lengua escrita es un extenso proceso de apropiación cultural que requiere del deseo de quien aprende; que convoca a sus recursos subjetivos, comunicativos, lingüísticos y cognitivos; que aprender implica tiempo y los tiempos de cada niño/a son singulares. Que se necesita de intervenciones pedagógicas que promuevan aprendizajes significativos, entendiendo que las diferencias son inherentes a nuestra condición humana y que, por lo tanto, debieran ser valoradas. Que el contexto familiar debe ofrecer oportunidades de encuentro con la lectura y la escritura contribuyendo a promoverlas, aunque no las determine, de allí el rol fundamental de la escuela; que la biología no es el único factor que pudiera obturar el aprendizaje escolar. Que las dificultades deben ser atendidas, pero que no necesitan ser nombradas en términos relativos a patologías porque, en reiteradas ocasiones, no responden a ningún cuadro específico sino a la singularidad de cada sujeto.

Es preciso problematizar esta realidad que atenta contra el derecho a aprender de las niñas y los niños. El derecho a aprender con errores, con aciertos y con tiempo. Tiempos siempre distintos, porque distintos son todas las niñas y todos los niños.

\section{REFERENCIAS}

Alvarado, M. (2013). Escritura e invención en la escuela. Fondo de Cultura Económica.

Asociación Americana de Psiquiatría. (2014). DSM 5. Manual Diagnóstico y Estadístico de los Trastornos Mentales. Médica Panamericana.

Baquero, R. (1997). Vigotsky y el aprendizaje escolar. Aique.

Beaugrande, R. A. y Dressler, W. U. (1997). Introducción a la lingüística del texto. Ariel.

Bereciartua, G. (2008). Teoría de la mente y clases textuales: Un estudio sobre la capacidad infantil para inferir un problema y resolverlo discursivamente

en un texto escrito. Tesis Doctoral sin publicar.

Bernasconi, P. (2010). Cuero negro, vaca blanca. La Brujita de Papel.

Bettelheim, B. y Zelan, K. (1983). Aprender a leer. Biblioteca de bolsillo. 
Revista de la Escuela de Ciencias de la Educación. 2022, Año 18 1(17). 97-110.

Enero a junio. Felice, M.F. La educación como práctica de "domesticación": la singularidad y la diversidad amenazadas.

Blanco, R. (1999). Hacia una escuela para todos y con todos. Boletín No 48 del Proyecto Principal de Educación para América Latina y el Caribe. Oficina Regional de Educación de la UNESCO.

Castorina, J. A. (2012). Epistemología y psicologías genéticas. Lugar Editorial.

Ferreiro, E. (1991). La construcción de la escritura en el niño. Revista Iberoamericana Lectura y Vida.

Ferreiro, E. (1993). Alfabetización de niños en América Latina. Proyecto Principal de Educación. Boletín 32.

Ferreiro, E. (1994). Diversidad y proceso de alfabetización: de la celebración a la toma de conciencia. Revista Iberoamericana Lectura y Vida. Año 15 (3).

Ferreiro, E. (2000). Leer y escribir en un mundo cambiante. Conferencia en las Sesiones Plenarias del 26 Congreso de la Unión Internacional de Editores, CINVESTAV.

Ferreiro, E. (2007). Las inscripciones de la escritura. Editorial de la UNLP.

Freire, P. (2004). La educación como práctica de la libertad. Siglo XXI.

Freire, P. (2015). Pedagogía del oprimido. Siglo XXI.

Ley Nacional de Educación no. 26.206. 28 de diciembre de 2006. https://www.argentina.gob.ar/sites/default/files/ley-de-educ-nac58ac89392ea4c.pdf

Puiggrós, A. (1990). Historia de la educación en Argentina I. Galerna.

Pètit. M. (2015). Leer el mundo. Experiencias actuales de transmisión cultural. Fondo de Cultura Económica.

Simons, M. y Masschelein, J. (2014). Defensa de la escuela. Una cuestión pública. Miño \& Dávila.

Vygotsky, L. (1977). Pensamiento y lenguaje. La Pléyade 